\title{
OPTIMAL WIND/SOLAR ENERGY MIX FOR RESIDENTIAL NET ZERO-ENERGY BUILDINGS
}

Janar KALDER, Estonian University of Life Sciences, Institute of Technology, Chair of Energy Application Engineering, Fr.R.
Kreutzwaldi 56, 51014 Tartu, Estonia, janar.kalder@emu.ee Alo ALLIK, Estonian University of Life Sciences, Institute of Technology, Chair of Energy Application Engineering, Fr.R. Kreutzwaldi 56, 51014 Tartu, Estonia, alo.allik@emu.ee

Hardi HÕIMOJA, Estonian University of Life Sciences, Institute of Technology, Chair of Energy Application Engineering, Fr.R. Kreutzwaldi 56, 51014 Tartu, Estonia, hardi.hoimoja@emu.ee

Erkki JÕGI, Estonian University of Life Sciences, Institute of Technology, Chair of Energy Application Engineering, Fr.R. Kreutzwaldi 56, 51014 Tartu, Estonia, erkki.jogi@emu.ee

Mart HOVI, Estonian University of Life Sciences, Institute of Technology, Chair of Energy Application Engineering, Fr.R. Kreutzwaldi 56, 51014 Tartu, Estonia, mart.hovi@emu.ee

Maido MÄRSS, Eesti Energia Ldt., Department of Renwable Energy, PV Project manager, Lelle 22, 11318 Tallinn, Estonia, maido.marss@energia.ee

Jarek KURNITS KI, Tallinn University of Technology, School of Engineering, Department of Civil Engineering and Architecture, Ehitajate tee 5, 10985 Tallinn, Estonia, jarek.kurnitski@ttu.ee

Jevgeni FADEJEV, Tallinn University of Technology, School of Engineering, Department of Civil Engineering and Architecture, Ehitajate tee 5, 10985 Tallinn, Estonia, Jevgeni.fadejev@ttu.ee

Heiki LILL, Estonian University of Life Sciences, Tartu Technology College, Fr.R. Kreutzwaldi 56, 51014 Tartu, Estonia, heiki.lill@emu.ee

Algirdas JAS INS KAS, Aleksandras Stulginskis University, Faculty of Agricultural Engineering, Institute of Agricultural Engineering and Safety, Studentu str. 15, Akademija, LT-53362 Kaunas reg., Lithuania, algirdas.jasinskas@asu.lt

Andres ANNUK, Estonian University of Life Sciences, Institute of Technology, Chair of Energy Application Engineering, Fr.R. Kreutzwaldi 56, 51014 Tartu, Estonia, andres.annuk@emu.ee_(corresponding author)

\begin{abstract}
The article is concentrated on the energy storage problems arising from microgeneration in private households. The case study involves a small-scale wind and solar electricity production set in a net zero-energy building. Both the net zero-energy building and the microgeneration units are connected to an utility grid. The current article serves to confirm the hy pothesis, that the self consumption is at its maximum with the annual 70/30 wind and solar energy mix of in favour of the wind. The maximal self consumption at no additional energy storage in a net zero-energy building is studied as well. Produced and consumed energies are equal, which satisfies the requirements for a net zero-energy building with the utility grid acting as an energy buffer. The consumed energy is used to operate a heat pump, heat up ventilation supply air, run ventilation fans, supplying non-shiftable loads (white goods, TV, lighting etc), heat up domestic hot water via heat pump. To express self consumption, we use the term of supply cover factor, which describes optimally the directly consumed energy in relationship to net consumption or production. In annual scale, the cover factors for a net zero-energy building are equal as the production and consumption are equal as well. Also, seasonal variations in self consumption are studied. According to study results, the annual maximal supply cover factor in a net zero-energy building is 0.375 with $70 / 30 \mathrm{wind} / \mathrm{solar}$ mix. Seasonally, the self consumption is at its maximum in summer when the supply cover factor equals to 0.49 .
\end{abstract}

Keywords: demand response, supply cover factor, load shifting, net zero-energy building, solar energy, wind energy

\section{INTRODUCTION}

Net zero-energy building is a building where the energy balance for the end of a year is equal to 0 (Directive..., 2010). Usually, a net zero-energy building is tied to an utility grid. Throughout a year, the utility grid acts as an energy storage medium. Among the renewable energy sources, the solar and wind have the longest historical records with growing acceleration numbers during the recent decades (Kaldellis and Zafirakis, 2011). The wind and solar share in the overall energy mix is growing mainly thanks to the new installations, the micro generation owes much of its popularity to the EU requirements on the net zero-energy buildings (Directive..., 2012). The variance and unpredictability of wind and solar generation is a well-known fact (Allik and Annuk, 2016 ). To compensate the stochastic character of these energy sources, several local demand side management (DSM) technologies are applied. One of the many possibilities is

Copyright (C) 2017 The Authors. Published by Aleksandras Stulginskis University. This is an open-access article distributed under the terms of the Creative Commons Attribution License (CC-BY 4.0), which permits unrestricted use, distribution, and reproduction in any medium, provided the original author and source are credited. 
the application of heat pump loads, discussed in the current paper (Vanhoudt et al., 2014; Elkinton et al., 2009). Previously, only solar-based energy input was considered for net zero-energy buildings (Luthander, 2015). The paper aims to study the share of self consumption in a net zero-energy building under different conditions and at seasonal level. Finally, the conditions for maximal self consumption is found.

\section{METHODS}

The wind generator and solar panel production graphs were recorded on a building's roof at coordinates $58^{\circ} 23^{\prime} 19^{\prime}$, N, 26 $41^{\prime} 37^{\prime \prime}$ E in the city of Tartu, Estonia. The network analyzer Janitza UMG 605 (Janitza..., 2017) with current transformers Circutor P2 TC5 M70312 provided data acquisition (Circutor...., 2017). The recorded data series begin on December 1, 2015 and end on November 30, 2016, covering all four seasons. The energy production data was logged as averaged values at 5-minute intervals, the calculations are based on the sum energies over 5-minute periods. The annual output energy of production units is scaled according to the consumption, being equal to the annual consumption in any circumstance.

Figure 1 presents fundamental scheme of the zero energy building with energy supply microdevices and connection to the grid. Non-shiftable loads such as white goods are presented as a separate component.

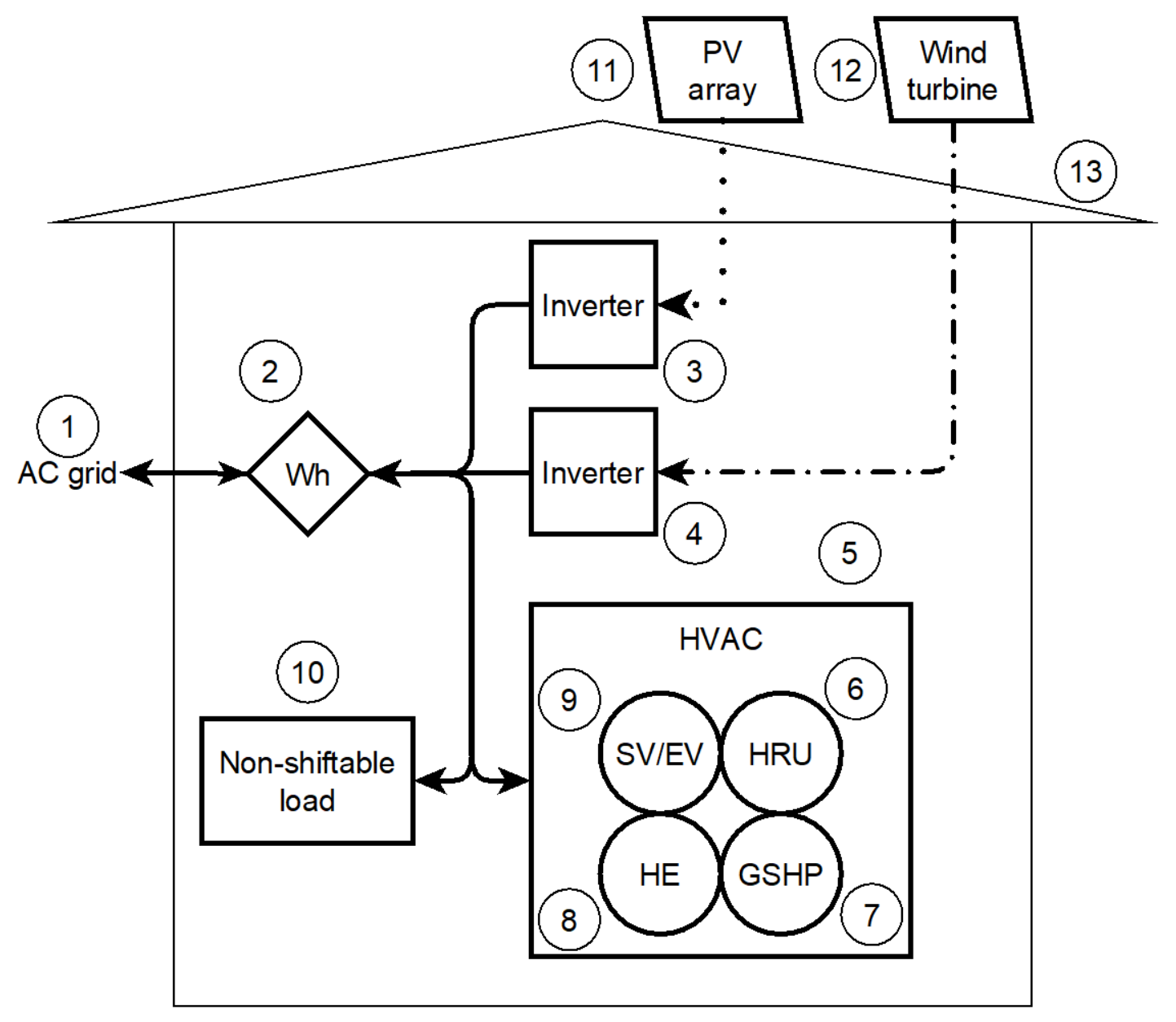

Figure 1. Principal diagram of the studied solution

where 1 - AC grid connection; 2 - Two way electrical energy meter; 3 - Inverters for solar panels; 4 - Inverters for wind turbine; 5 - HVAC unit consisting: 6 - Heat recovery unit (HRU), 7 - Ground source heat pump (GSHP), 8 - Supply air heating element (HE), 9 - Supply and exhaust fans (SV/EV); 10 - Non shiftable loads; 11 - PV panel array; 12 - Wind turbine; 13 - Zero energy building.

Initial data for this study consist of a typical annual net zero-energy building electrical load (Fig. 2) that includes heat pump compres sor, ventilation supply air heat load, fan load and non-shiftable load graphs (lighting, TV, white goods etc). The annual electricity consumptions are $W_{h p}=1835 \mathrm{kWh} / \mathrm{y}$ for the heat pump, $W_{v h}=1628 \mathrm{kWh} / \mathrm{y}$ for ventilation supply air heating, $W_{v v}=1335 \mathrm{kWh} / \mathrm{y}$ for operating the fans, $W_{n s}=2802 \mathrm{kWh} / \mathrm{y}$ for the non-shiftable loads. The total electricity consumption is $W_{t}=7600 \mathrm{kWh} / \mathrm{y}$. 


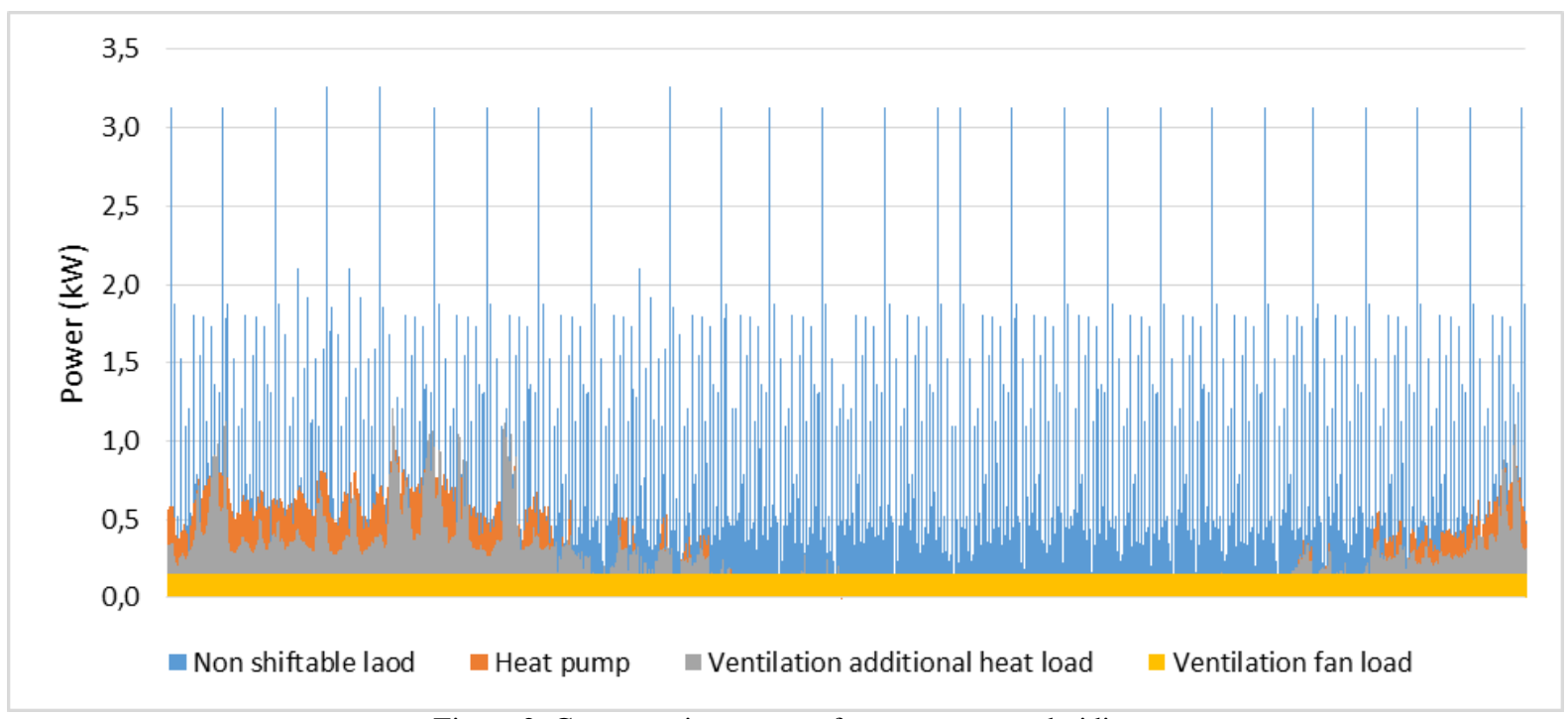

Figure 2. Consumption curves of net zero energy buiding

The energy balance of the given net zero energy buildings described as:

$$
W_{h p}+W_{v h}+W_{v v}+W_{n s}-W_{p v}-W_{w}=0
$$

where $W_{p v}$ - annual solar electricity generation, $\mathrm{kWh} / \mathrm{y}, W_{w}$ - annual wind electricity generation, $\mathrm{kWh} / \mathrm{y}$.

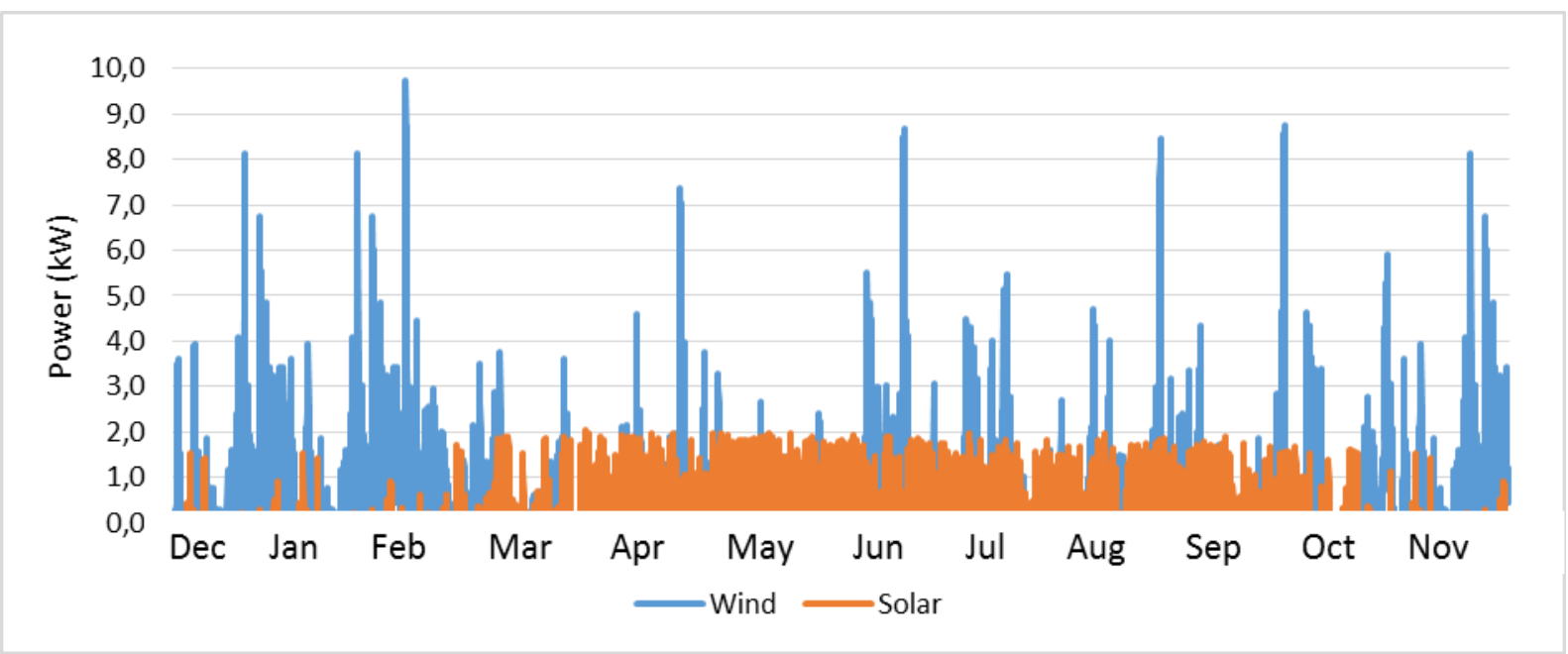

Figure 3. Production graphs of the wind generator and solar panels

Net zero-energy building was modelled as a two-floor single family house with $143.9 \mathrm{~m}^{2}$ heated area (Fig. 4) located in Tallinn, Estonia. Modelling was performed in IDA-ICE energy simulation environment and MatLab simulation software. Annual energy demand of a heat pump and air handling unit (AHU) supply air heating and fans was obtained in IDA-ICE, where non-shiftable load (Fig. 2) was applied as a reference for internal gains modelling. Climatic conditions in IDA-ICE were defined according to Estonian test reference year (TRY), which consists of outdoor climate data array for indoor climate and energy calculations, collected from the climatic databetween 1970 and 2000 all over Estonia and composed according to Estonian standard (EVS..., 2005) or similar requirements (Kalamees and Kurnitski, 2006). MatLab was applied for calculating boilers' energy balances at every time step, with results presented in Fig ure 5, Figure 6 and Table 1 .

The current simulation is based on the scaled production graphs of the following electricity microgeneration units: horizontal axis, $3.5 \mathrm{~kW}$, passive yaw control permanent magnet generator (Sonkyo..., 2015), with SMA Sunny Boy 3600TL inverter (SMA..., 2012) and $2.5 \mathrm{~kW}$ PV array (DelSolar $250 \mathrm{~W}$ D6P250B3A) (Yingli..., 2017), oriented towards South with $40^{\circ}$ elevation. A $2.75 \mathrm{~kW}$ grid tie inverter (SOLIVIA $2.5 \mathrm{EU}$ G3) (SMA..., 2012) is used for converting DC to AC. Figure 4 presents single family house model placement.

The production data for both devices is scaled according to the actual load, which results in peak wind turbine power of $12.78 \mathrm{~kW}$ and peak PV power of $2.23 \mathrm{~kW}$. Devices were sized on the 70/30 annual generation mix in favour of the wind turbine (Garalis et al., 2011; Annuk et al., 2011; Annuk et al., 2013). The wind turbine is located in urban conditions with a low capacity factor (ratio between actually generated energy and the theoretical energy if operating continuously at installed power) of $\mathrm{CF}=0.06$, as for $\mathrm{PV}$ panels, $\mathrm{CF}=0.11$. 

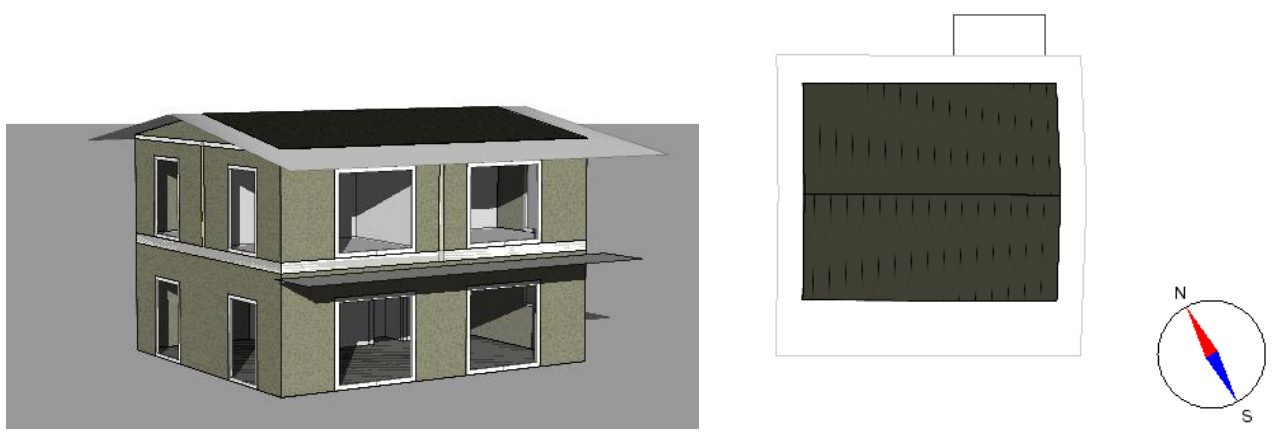

Figure 4. Single family house model and its orientation in IDA-ICE

The cover factors both express the relationship between locally produced and directly consumed electricity (Allik et al., 2016; Baetens et al., 2012):

$$
Y_{S}=\frac{\int_{t_{0}}^{t_{1}} P_{D} d t+\int_{t_{1}}^{t_{2}} P_{S} d t}{\int_{t_{0}}^{t_{2}} P_{S} d t} \quad Y_{D}=\frac{\int_{t_{0}}^{t_{1}} P_{D} d t+\int_{t_{1}}^{t_{2}} P_{S} d t}{\int_{t_{0}}^{t_{2}} P_{D} d t}
$$

where $P_{S}$ is the local power supply and $P_{D}$ the local power demand. The time when $P_{D}(t) \leq P_{S}(t)$ is denoted as $t_{0} \ldots t_{1}$, and $t_{1} \ldots t_{2}$ is the time when $P_{D}(t)>P_{S}(t)$.

The supply cover factor $Y_{S}$ is a measure for the self-consumption of locally produced renewable energy. Similarly, the demand cover factor $Y_{D}$ is defined as 'the ratio to which the energy demand is covered by the local supply' and indicates the 'self-generation' (Vanhoudt et al., 2014). If production and consumption are equal, the supply and demand cover factors are equal as well (Luthander, 2015). Further, for sake of clarity, we consider only the supply cover factor, as it expresses the ratio of self consumption into the consumed energy and not into the produced energy, described by the demand cover factor..

\section{RESULTS AND DISCUSSION}

In case of a net zero energy building with no additional energy storage units applied, one of the possibilities to optimize self consumption is to change the annual wind/solar energy shares. Figure 5 describes the impact of different annual wind/solar electricity production shares on the supply cover factor.

According to Figure 5, the supply cover factor peaks at $Y=0.375$ when annual wind/solar mix is $70 / 30$ in favour of the wind energy. This production mix has been confirmed in a wider scale, as show the similar calculations for Greece (Caralis, 2011) and Estonia (Annuk et al., 2012; Annuket al.,2011). The cover factors can be augmented with additional energy storage units inside the system.

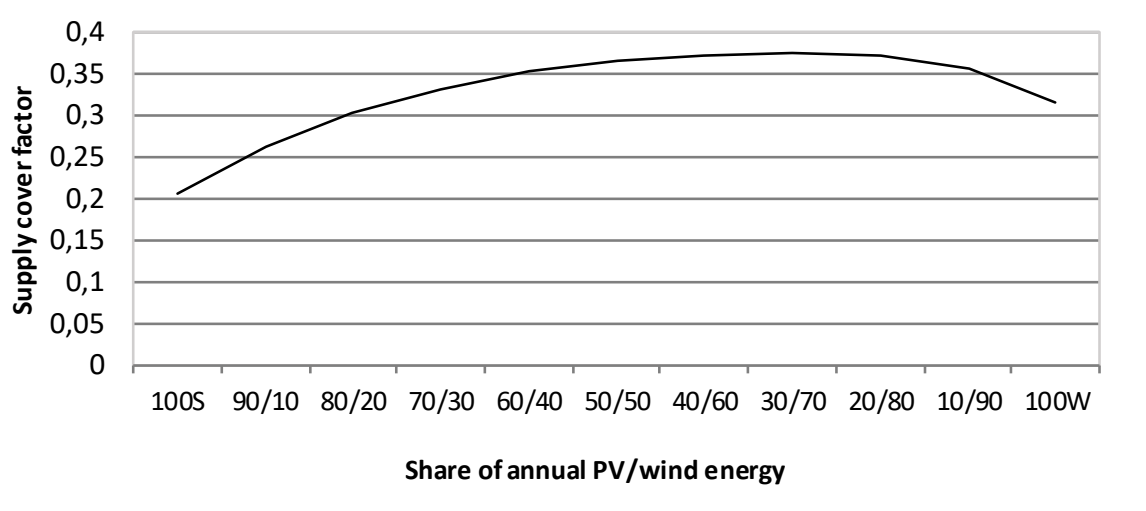

Figure 5. Impact of different annual wind/solar electricity shares on the cover factor

Figure 6 illustrates the same process at seasonal level. The supply cover factor has its lowest value in winter, when the power generation is maximum at 100/0 wind/solar mix, as $100 \%$ of the electricity is supposed to be provided by the wind generator and the net sum of solar irradiation is negligible. However, at seasonal level, the supply cover factor in summer is the highest: higher than 0.5 in very large range of energy mix values. If energy mix were $0 / 100$, i.e. $100 \%$ solar, then values for all seasons would be quite apart differing from 0.06 to 0.5 . On only wind-powered supply, cover factors are in range of 0.2 in spring to 0.4 in winter. During summer, the supply cover factor has the highest value, when the wind and solar energy productions are more or less equal (Table 1). 


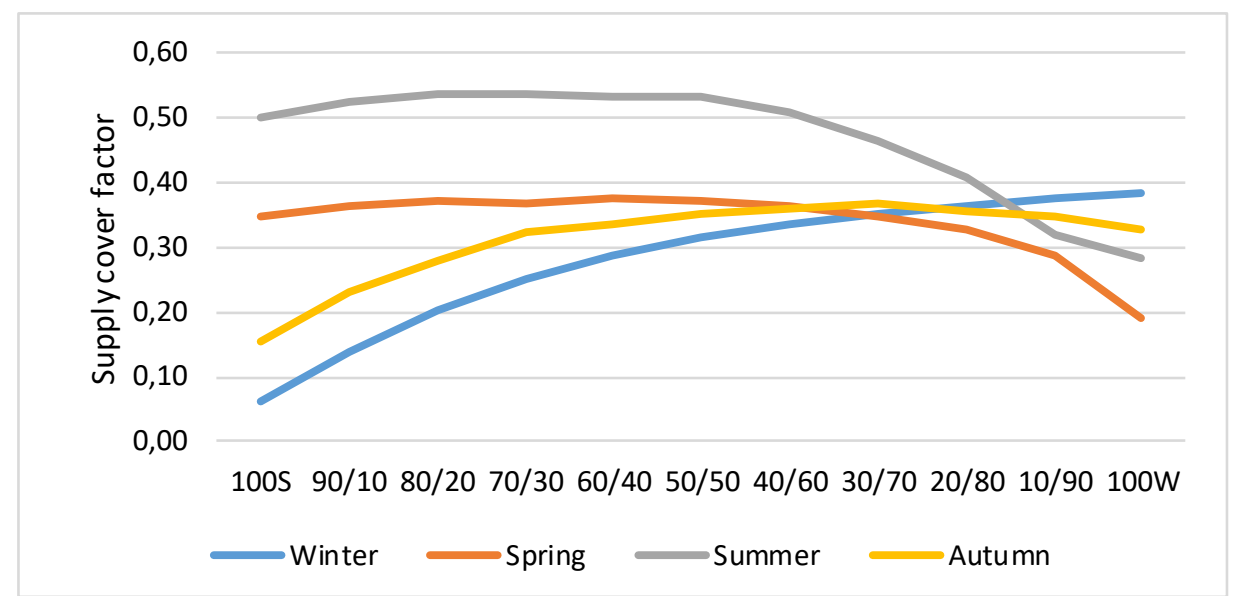

Figure 6. Impact of different seasonal wind/solar electricity shares on the supply cover factor

Table 1. Seasonal wind and solar electricity productions at annual wind/solar share of 70/30

\begin{tabular}{|l|l|l|l|l|}
\hline Parameters & Winter & Spring & Summer & Autumn \\
\hline Solar energy production, kWh & 106.4 & 915.8 & 894.9 & 362.9 \\
\hline Wind electricity production, kWh & 1931.3 & 709.7 & 1233.4 & 1446.1 \\
\hline Wind/solar mix, \% & $95 / 5$ & $43 / 67$ & $58 / 42$ & $80 / 20$ \\
\hline Demand, kWh & 3082.5 & 1653.4 & 1040.2 & 1825.0 \\
\hline Total production & 2037.7 & 1625.5 & 2128.3 & 1809.0 \\
\hline$Y_{S}$ & 0.35 & 0.35 & 0.49 & 0.37 \\
\hline
\end{tabular}

Detailed simulation results of 70/30 annual energy mix are presented in Table 1. Highest demand and production appears in winter resulting in supply cover factor of $Y_{S}=0.35$. On the seasonal basis supply coverfactor slightly varies in range of 0.35-0.49 with its peak value obtained in summer period. Highest value of supply cover factor in summer can be explained by low demand. Increase in supply cover factors can be obtained with the application of storage devices e.g. battery. For instance, if we use instead of wind generator and PV panels energy source with constant output power, $P=0.868 \mathrm{~kW}$, what covered electricity supply $7600 \mathrm{kWh} / \mathrm{y}$, then $Y_{S}=0.71$.

\section{CONCLUSION}

The article discusses maximising self consumption in net zero-energy buildings without additional energy storage units. One can claim, that the 70/30 mix is an universal one regardless of latitude and local wind conditions.

- At annual wind/solar energy mix of $70 \% / 30 \%$ in favour of wind, self consumption reaches its peak resulting in supply cover factor of $Y=0.375$.

- Application of wind power as the only energy source in a net zero-energy building results in supply cover factor of $Y_{S}=0.323$.

- Application of $100 \%$ PV panels produces supply cover factor of $Y_{S}=0.234$.

\section{ACKNOWLEDGEMENTS}

The Estonian Centre of Excellence in Zero Energy and Resource Efficient Smart Buildings supported this research and Districts, ZEBE, grant TK146 funded by the European Regional Development Fund.

\section{REFERENCES}

1. Allik, A., Annuk, A. 2016. Autocorrelations of power output from small scale PV and wind power systems. IEEE Conference Publications: 2016 IEEE International Conference on Renewable Energy Research and Applications (ICRERA). pp. $279-284$. Birmingham, UK. https://doi.org/10.1109/ICRERA.2016.7884552

2. Allik, A., Märss, M., Uiga, J., Annuk, A. 2016. Optimization of the inverter size for grid-connected residential wind energy systems with peak shaving. Renewable Energy, Vol. 99, pp. 1116-1125. https://doi.org/10.1016/j.renene.2016.08.016

3. Annuk, A., Allik, A., Pikk, P., Toom, K., Jasinskas, A. 2012. Power balancing possibilities for a small wind-PV panel hybrid system for a nearly autonomous unit consumer. Ed. Silvio Kosutic. Actual Tasks on Agricultural on Agricultural Engineering, pp. 485-494.

4. Annuk, A., Allik, A., Pikk, P., Uiga, J., Tammoja, H., Toom, K., Olt, J. 2013. Increasing renewable fraction by smoothing con sumer power charts in grid-connected wind-solar hybrid systems. Oil Shale, Vol. 30(2S), pp. $257-267$. https://doi.org/10.3176/oil.2013.2S.06

5. Annuk, A., Pikk, P., Kokin, E., Karapidakis, E. S., Tamm, T. 2011. Performance of wind-solar integrated grid connected energy system. Agronomy Research, Vol. 9, Iss. 1-2, pp. 273-280. 
6. Baetens, R., De Coninck, R., Van Roy, J., Verbruggen, B., Driesen, J., Helsen, L., Saelens, D. 2012. Assessing electrical bot tlenecks at feeder level for residential net zero-energybuildings by integrated sy stem simulation. Applied Energy, Vol. 96, pp. 74-83. https://doi.org/10.1016/j.apenergy.2011.12.098

7. Caralis, G., Delikaraoglu, S., Zervos, A. 2011. Towards the optimum mix between wind and PV capacity in the Greek power system. European Wind Energy Conference \& Exhibition Scientific Proceedings, pp. 75-79.

8. Circutor. M 7 Current transformers and shunts. Available at http://www.samey.is/vorur/Circutor/ M7_01_GB.pdf (accessed on $10 / 06 / 2017)$

9. Civic Solar. Yingli Solar YL 245 P-29b 245W Poly SLV_WHT Solar Panel. Available at https://www.civicsolar.com/product/y ingli-solar-yl-245-p-29b-245w-poly-slvwht-solar-panel. (accessed on 10/06/2017)

10. Directive 2010/31/EU of the European Parliament and of the Council of 19 May 2010 on the energy performance of buildings. 2010. Official Journal of the European Union, No. 153, pp. 13-35.

11. Directive 2012/27/EU of the European Parliament and of the Council of 25 October 2012 on energy efficiency, amending Directives 2009/125/EC and 2010/30/EU and repealing Directives 2004/8/EC and 2006/32/EC. 2012. Official Journal of the European Union, No. 315, pp. 1-56.

12. Elkinton, M.R., McGowan, J.G., Manwell, J.F. 2009. Wind power systems for zero net energy housing in the United States. Renewable Energy, Vol. 34, pp. 1270-1278. https://doi.org/10.1016/j.renene.2008.10.007

13. Estonian centre for standardisation. 2005. Hy grothermal performance of buildings - Calculation and presentation of climatic data - Part 4: Hourly data for assessing the annual energy use for heating and cooling. Available at https://www.evs.ee/tooted/evs-eniso-15927-4-2005 (accessed on 10/06/2017)

14. Janitza electronics GmbH. Power Quality Analyser UMG 605 Operating manual and technical data. Available at https://www.janitza.com/manuals.html?file=files/download/manuals/current/UMG605/Janitza-Manual-UMG605-en.pdf (accessed on 10/06/2017)

15. Kalamees, T., Kurnitski, J. 2006. Estonian test reference year forenergy calculations. Proceedings of the Estonian Academy of Sciences, Vol. 12, pp.40-58.

16. Kaldellis, J.K., Zafirakis, D. 2011. The wind energy (r)evolution: a short review of a long history. Renewable Energy, Vol. 36, pp. 1887-1901. https://doi.org/10.1016/j.renene.2011.01.002

17. Luthander, R., Widen, J., Nilsson, D., Palm, J. 2015. Photovoltaic self consumprion in buidings: A review. Applied Energy, 142, pp. 80-94. https://doi.org/10.1016/j.apenergy.2014.12.028

18. SMA. 2012. Sunny Boy 3000TL / 4000TL / 5000TL. Available at http://files.sma.de/dl/5692/SB5000TL-DDE112440W.pdf (accessed on 10/06/2017)

19. Sonkyo Energy. 2015. Windspot $3.5 \mathrm{Kw}$. Available at http://usa.windspot.es/home-wind-turbines/products/89/windspot-35-kw (accessed on 10/06/2017)

20. Vanhoudt, D., Gey sen, D., Claessens, B., Leemans, B., Jespers, L., Van Bael, J. 2014. An actively controlled residential heat pump: potential on peak shaving and maximization of self-consumption of renewable energy. Renewable Energy, Vol. 63, pp.531-543. https://doi.org/10.1016/j.renene.2013.10.021 